"All along the curves" - Bridging the gap between comparative statics and simultaneous econometric models

\author{
Eivind Hestvik Brækkan ${ }^{12}$ \\ $\varnothing$ ystein Myrland ${ }^{3}$
}

\footnotetext{
${ }^{1}$ Analyst, Capia AS, postbox 109, 9252 Tromsø, Norway

${ }^{2}$ Corresponding author: eivind@capia.no +47 95201322

${ }^{3}$ Professor, The School of Business and Economics, Faculty of Biosciences, Fisheries and Economics, UiT The Arctic University of Norway. N-9037 Tromsø, Norway
} 
"Stripped of the detail, commodity prices do indeed reflect shifts in supply relative to demand" (Tomek 2000, p. 130).

Econometric simultaneous equation models are useful tools for understanding supply and demand behavior. They provide us with estimated marginal effects of changes in exogenous variables on demand and supply, often referred to as structural elasticities or simply elasticities. Structural elasticities, also known as Marshallian elasticities, provide valuable information on how changes in prices, income, substitute prices, technological progress or other variables affect supply or demand. While the results can provide sound and significant elasticities that indicate the relationship between variables, the results per se do not provide insight into the causes of changes in prices and quantities (Buse 1958). An interesting example is the spike (and subsequent collapse) in prices of major agricultural food commodities before and after the financial crisis in 2008, which has been heavily debated and attributed to numerous potential explanations (Gilbert 2010; Gilbert and Morgan 2010). Thus, it is important to understand causes of such changes, both in the short and long run, and especially in specific periods where large changes occur. A popular approach for determining the impacts of exogenous variables on prices and quantities are comparative static models known as Equilibrium Displacement Models (EDM's) (Muth 1964; Alston et al. 1998; Wohlgenant 2011). Typically, an EDM is used to determine the impacts of a one-time shift in one or more exogenous variables, often relying on estimates of elasticities from previous research. In this paper, we bridge the gap between comparative statics and the econometric simultaneous equation model by using the results from the econometric model to determine the impacts of the exogenous variables in each period. The final bridging of the gap is completed by calculating and including unexplained supply and demand shifts into the model. While the exogenous variables in the model accounts for deterministic impacts, the unexplained demand and supply shifts capture the stochastic 
impacts on endogenous variables. The approach for calculating unexplained shifts is similar (but not identical) to accounting for productivity growth through estimating the well-known Solow residual (Solow 1957). The Solow residual has been coined "some sort of measure of our ignorance” (Abramovitz 1993, p. 218), which would also be an accurate description of our unexplained supply and demand shifts. The residual is also important in the Stochastic Frontier Analysis (SFA) literature. In stochastic production frontier models, introduced by Aigner, Lovell and Schmidt (1977), and Meeusen and van Den Broeck (1977), the error term is split into a random noise component, and a non-negative technical inefficiency component. Together they constitute a compound error term.

Including unexplained shifts in our model lets us determine the extent to which unknown (stochastic) impacts on the supply and demand side contribute to price and quantity changes.

Our approach provides answers to a range of questions that are easily forgotten when interpreting results from econometric simultaneous equation models. These are:

1) What are the reduced form elasticities for the exogenous variables?

2) How can we use results from the econometric model to explain what happens in a market over time?

3) What is the relative impact of changes in each exogenous variable on changes in price and quantity?

4) To what extent are changes in price and quantity over time caused by changes in the exogenous variables?

5) Are supply or demand shocks more important causes of unexplained changes in price and quantity?

To answer these questions we need to put the structural elasticities to work. A solution to the first question is simple. Specify a comparative static model (an EDM) that contains the 
variables and structural elasticities, and solve the model in reduced form (Piggott 1992). Such a model will typically consist of one or more supply and demand equations, and an equilibrium condition. Solving the model provides reduced form elasticities, i.e. the net effects on price and quantity from changes in each exogenous variable. The second and third question require a bit more effort. While comparative static models use structural elasticities to determine the effects of one-time shifts in exogenous variables, they do not typically address the causes of changes over time. To address changes over time, one can solve the comparative static model for each period where data are available. Observed changes in each exogenous variable can predict the net changes in endogenous variables for each period in question. The results show the changes in price and quantity caused by changes in each exogenous variable, both period-to-period as well as over time. Given these results, we can address question four. Compare predicted and observed changes in price and quantity to determine the extent to which changes in endogenous variables are caused by changes in exogenous variables. We will (almost) always observe that predicted changes in price and quantity are not identical to observed changes. This brings us to the fifth question. In order to determine the source of unexplained changes in price and quantity, we use the difference between predicted and observed equilibrium quantity to calculate unexplained changes in supply and demand, which we include as exogenous variables in the comparative static model. This allows us to determine the relative importance of supply and demand shocks on changes in endogenous variables, both from period to period as well as the cumulative impact over time. Including unexplained shifts bridges the gap between comparative statics and simultaneous econometric models.

To demonstrate the application we replicate a simple two-stage least squares supply and demand model provided by Epple and McCallum (2006) (hereafter E\&M). E\&M illustrate the econometric results by deriving and plotting the implied demand and supply equations in levels for two different periods, ignoring the error terms. We develop an annual demand and supply 
model within an EDM framework to determine the yearly impacts of exogenous variables. We further extend the traditional use of EDMs by determining unidentified causes of shifts in supply and demand per period, as well as their impacts on prices and quantities. The following section introduces E\&M’s econometric model.

\section{The Econometric Model}

E\&M estimated the following two-stage least squares supply and demand equations for the US broiler chicken market: ${ }^{4}$
(1) $\operatorname{qprod}_{t}^{a}=\alpha_{0}+\varepsilon_{p} p_{t}+\varepsilon_{p f} p f_{t}+\alpha_{t} T I M E_{t}+\alpha_{q} q p r o d=u_{t-1}^{a}+u_{t}$
(2) $d q_{t}=\eta_{p} d p_{t}+\eta_{y} d y_{t}+\eta_{p b} d p b_{t}+\mathrm{v}_{\mathrm{t}}$ (Supply)

where lowercase letters indicate that variables are expressed in logarithms, and $d$ denotes that variables are expressed in $\log$ difference form $\left(d x_{t}=\ln \left(\frac{X_{t}}{X_{t-1}}\right)\right)$. In the supply equation, aggregate production $\left(\operatorname{qprod}_{t}^{a}\right)^{5}$ depends on a constant term $\left(\alpha_{0}\right)$, own-price $\left(p_{t}\right)$, and a set of supply shift variables. E\&M identified the relevant shift variables to be the price of feed $\left(p f_{t}\right)$, a time trend $\left(T I M E_{t}\right)$ reflecting technical change, and last year's production ( $\left.q p r o d_{t-1}^{a}\right)$ to reflect adjustment costs in production. In the demand equation, changes in consumption per capita $\left(q_{t}\right)$ depend on changes in chicken price $\left(p_{t}\right)$ and a set of demand shift variables. The demand shift variables identified by E\&M are income $\left(y_{t}\right)$ and the price of beef $\left(p b_{t}\right)$. E\&M show that using the two-stage least squares procedure is preferred to ordinary least squares.

\footnotetext{
${ }^{4}$ In E\&M’s article supply and demand are equations (13) and (12).

${ }^{5}$ We use E\&Ms notation, where superscript $a$ refers to aggregate.
} 
Their elasticity estimates are statistically significant and consistent with theory. ${ }^{6}$ The elasticities in equations (1) and (2) are our well-known structural elasticities. They do not take into account the general equilibrium effects of changes in the endogenous variables in the system. In other words, they can be used to predict the impact on demand from a 3\% increase in income, which is simply the estimated elasticity of income $\eta_{y}$ times $3 \%$, but one cannot immediately determine the net effect on price, quantity consumed per capita or aggregate production. To be able to do this, it is time to put the elasticities to work.

\section{The Economic Model}

Assuming E\&M's econometric model is an accurate description of the US broiler chicken market ${ }^{7}$, we now specify a comparative static model of the market. We represent the economic model by three equations, supply, demand, and an equilibrium condition. First, write (1) and (2) in log differential form:

(3) dqprod $_{t}^{a}=\varepsilon_{p} d p_{t}+\varepsilon_{p f} d p f_{t}+\alpha_{t}+\alpha_{q} d q p r o d=1$

(4) $d q_{t}=\eta_{p} d p_{t}+\eta_{y} d y_{t}+\eta_{p b} d p b_{t}$

Note that the time trend in the supply equation is now represented by the constant $\alpha_{t}$. To determine the net changes in price and quantity caused by shifts in the exogenous variables, we

\footnotetext{
${ }^{6}$ While more sophisticated models of supply and (or) demand could have been applied to illustrate the procedure, we prefer E\&M's 2006 model since it focuses on an interesting market with substantial changes in price and quantities over time, and the data used to estimate the model are publicly available.

${ }^{7}$ For a discussion and tests of potential econometric issues please refer to (Brumm et al. 2008). The authors find that the model is satisfactory also when applied to various tests for exogeneity, the strength of instruments, and spurious regression. A reviewer also asked whether adding a time trend to the demand equation would impact the results. Adding a time trend causes demand to be slightly less elastic (from -0.4 to -0.33 ) and a smaller income elasticity (from 0.84 to 0.52 ). However, the time trend is not significant, and we therefore choose to continue with E\&Ms specification.
} 
need to establish an equilibrium condition between supply and demand. Following E\&M, we express the relationship between aggregate production and consumption per capita as follows:

(5) $Q P R O D_{t}^{a}=Q_{t} \times P O P_{t}+X_{t}$

where $P O P_{t}$ and $X_{t}$ are population and quantity exported. E\&M suggest that major trends and changes in exports of US chicken are largely due to improvements in shipping technology and altering political relationships between the US and the two main foreign markets, Russia and Hong Kong. Hence, they argue that exports can be treated as exogenous, an assumption which is kept here as well. We express equation (5) in log differential form ${ }^{8}$ :

(6) dqprod $_{t}^{a}=\kappa D d q_{t}+\kappa D d p o p_{t}+\kappa d X x_{t}+\kappa D d q_{t} d p o p_{t}$

where $\kappa \mathrm{D}=\left(Q_{t-1} \times P O P_{t-1}\right) / Q P R O D_{t-1}^{a}$, and $\kappa X=1-\kappa D$ are shares of production consumed domestically and exported. ${ }^{9}$ For small changes in $Q$ and $P O P$, we can ignore the last term in equation (6). ${ }^{10}$ We now have a system of three equations: supply (3), demand (4), and the equilibrium condition (6), with three endogenous variables $\left(Q P R O D_{t}^{a}, Q_{t}, P_{t}\right)$, and seven exogenous variables $\left(P F_{t}\right.$, time, $\left.Q P R O D_{t-1}^{a}, Y_{t}, P B_{t}, P O P_{t}, X_{t}\right)$. Given appropriate estimates of the relevant elasticities, which are obtained from the econometric model, our

\footnotetext{
${ }^{8}$ An earlier version of the paper expressed the model in percentage change form. A reviewer and the editor noted that this implies that the demand and supply equations in levels are linear (see also Zhao et al. (1997) for a further discussion of expressing equations in percentage change or log differentials). Considering E\&Ms express the supply and demand equation in logs, we here express the model in log differentials. Note that this introduces a small error in the equilibrium equation (6), caused by using the approximation $\frac{z_{t}-z_{t-1}}{z_{t-1}} \approx \ln \left(\frac{z_{t}}{z_{t-1}}\right)$.

9 To see why $\kappa \mathrm{D}$ and $\kappa X$ refer to last period's shares, note that: $\frac{Q P R O D_{t}^{a}-Q P R O D_{t-1}^{a}}{Q P R O D_{t-1}^{a}}=$ $\frac{Q_{t-1} \times P O P_{t-1}}{Q P R O D_{t-1}^{a}} \frac{\left(Q_{t}-Q_{t-1}\right) \times P O P_{t-1}}{Q_{t-1} \times P O P_{t-1}}+\frac{Q_{t-1} \times P O P_{t-1}}{Q P R O D_{t-1}^{a}} \frac{\left(P O P_{t}-P O P_{t-1}\right) \times Q_{t-1}}{P O P_{t-1} \times Q_{t-1}}+\frac{X_{t-1}}{Q P R O D_{t-1}^{a}} \frac{X_{t}-X_{t-1}}{X_{t-1}}+$ $\frac{Q_{t-1} \times P O P_{t-1}}{Q P R O D_{t-1}^{a}} \frac{\left(Q_{t}-Q_{t-1}\right) \times\left(P O P_{t}-P O P_{t-1}\right)}{Q_{t-1} \times P O P_{t-1}}$, which simplifies to (6) after approximating the changes in variables by using log differentials.

${ }^{10}$ We will henceforth ignore the last term.
} 
economic model can now be solved to determine the price and quantity effects from changes in each of our seven exogenous variables. In matrix notation, the economic model can be expressed as follows:

\section{(7) $A Y=B Z$}

where $\mathbf{A}$ is a $3 \times 3$ matrix of parameters corresponding to the model's endogenous variables, $\mathbf{Y}$ is a $3 \times 1$ vector of endogenous variables, $\mathbf{B}$ is a $3 \times 7$ matrix of parameters corresponding to the model's exogenous variables, and $\mathbf{Z}$ is a $7 \times 1$ vector of exogenous variables. Pre-multiplying $\mathbf{B}$ by the inverse of $\mathbf{A}$ yields:

(8) $\mathbf{Y}=\mathbf{G Z}$

where $\mathbf{G}=\mathbf{A}^{\mathbf{- 1}} \mathbf{B}$ is a $3 \times 7$ matrix containing the model's full set of reduced-form elasticities. The reduced-form elasticities in equation (8) are also known as general equilibrium or total elasticities. They express the net effect of changes in the exogenous variables on the endogenous variables, taking into account changes in all endogenous variables. Thus, the net effect of a change in any exogenous variable depends on the set of structural coefficients in $\mathbf{B}$.

A potential issue with the specified model is that there may be unidentified factors that contribute to supply and demand shifts. This is illustrated by the fact that when solving the economic model for observed changes in exogenous variables in any given period, we can be almost certain that the predicted endogenous variables will not be identical to the observed ones (and this is indeed the case).

To account for shifts caused by other factors we introduce residuals to our model. Residuals, or unexplained shifts, can be interpreted as measures of our ignorance, comparable to the interpretation of the Solow residual (Abramovitz 1993, Solow 1957). Our approach is 
similar to that of Taylor and Taylor (1993) who measure unexplained growth in demand in the US telephone markets, and Brækkan et al. (2018) who use residuals to estimate the impacts of unknowns on demand for salmon. The procedure for calculating the unexplained demand shift is simple: let $v_{t}$ be the unexplained demand shift caused by factors like changes in taste, transportation costs, demographics, the introduction of new products, advertising, and any other factor not included in the economic model. If data on any variables of interest were available, one could of course include these in the econometric model, estimate corresponding elasticities, and include this in the economic model. Add the unexplained demand shift $v_{t}$ to demand equation (4):

$\left(4^{\prime}\right) d q_{t}=\eta_{p} d p_{t}+\eta_{y} d y_{t}+\eta_{p b} d p b_{t}+v_{t}$

For supply, let $u_{t}$ be the unexplained supply shift and add it to supply equation (3):

$\left(3^{\prime}\right) \operatorname{d} q p r o d_{t}^{a}=\varepsilon_{p} \mathrm{~d} p_{t}+\varepsilon_{p f} \mathrm{~d} p f_{t}+\alpha_{t}+\alpha_{q(-1)} \mathrm{d} q p r o d_{t-1}^{a}+u_{t}$

Using the estimated elasticities and observed values for all other variables in (3’) and (4') we calculate $v_{t}$ and $u_{t}$ for each period.

The unexplained shifts should not be mistaken for residuals from an econometric model; $v_{t}$ and $u_{t}$ are not used to estimate any elasticities nor have they any distributional properties as in an econometric model ${ }^{11}$.

\footnotetext{
${ }^{11}$ If (3') and (4') had been estimated econometrically and the estimated coefficients had been used to compute the unexplained shifts, $v_{t}$ and $u_{t}$ would of course be identical to the residuals from the econometric model. While estimating (4') provides results similar to the coefficients estimated in (2), estimating (3') yields nonsensical results. (4') and (2) are both expressed in log differences, while (1) and (3') are expressed in logs and log differences, respectively. This is probably why estimating (3') does not yield sensible results. Thus we continue using the coefficients estimated from EM's original model (equations (1) and (2)).
} 
Next, we determine the impacts of these unexplained shifts on prices and quantities. To do this we turn to our economic model which now includes the unexplained shifts. Our system now comprises three equations $\left(6,4^{\prime}, 3^{\prime}\right)$, with three endogenous variables $\left(Q P R O D_{t}^{a}, Q_{t}, P_{t}\right)$ and nine exogenous variables $\left(P F_{t}\right.$, time $\left., Q P R O D A_{t-1}^{a}, Y_{t}, P B_{t}, P O P_{t}, X_{t}, u_{t}, v_{t}\right)$

To solve the system, we again express the model in matrix notation, but index each equilibrium at each time period:

(9) $\Pi_{t} \mathbf{Y}_{t}=\Gamma_{t} Z_{t}$

where $\boldsymbol{\Pi}_{\mathbf{t}}$ is a $3 \times 3$ matrix of parameters corresponding to the model's endogenous variables, $\mathbf{Y}_{\mathbf{t}}$ is a $3 \times 1$ vector of endogenous variables, $\boldsymbol{\Gamma}_{\mathbf{t}}$ is a $3 \times 9$ matrix of parameters corresponding to the model's exogenous variables, and $\mathbf{Z}_{\mathbf{t}}$ is a $9 \mathrm{x} 1$ vector of exogenous variables, all in period t. In $\mathbf{Z}_{\mathbf{t}}, u_{t}$ and $v_{t}$ are the values obtained from (3') and (4'), the time variable is always 1 , while all other variables are expressed in log differences. Pre-multiplying equation (13) by the inverse of $\boldsymbol{\Pi}_{\mathbf{t}}$ yields:

(10) $\mathbf{Y}_{\mathbf{t}}=\mathbf{E}_{\mathrm{t}} \mathbf{Z}_{\mathrm{t}}$

where $\mathbf{E}_{\mathbf{t}}=\boldsymbol{\Pi}_{\mathbf{t}}^{-1} \boldsymbol{\Gamma}_{\mathbf{t}}$ is a 3 x 9 matrix containing the model's full set of total or reduced-form elasticities in period $t$, and $\mathbf{E}_{\mathbf{t}} \mathbf{Z}_{\mathbf{t}}$ contains the relative effect on the endogenous variables from the changes in each exogenous variable. Our system consists of $t$ different equilibria, one for 
each point in time. ${ }^{12}$ Using the replicated structural elasticities from E\&M’s study, we solve equation (10) for each data point $t$. This gives us the net (total) annual impacts on price and quantities from changes in all exogenous variables. We also want to calculate the annual individual impacts from each exogenous variable. We do this for each period by calculating the Hadamard product (element-by-element matrix multiplication) of matrices $\mathbf{E}_{\mathbf{t}}$ and $\mathbf{Z}_{\mathbf{t}}^{\mathbf{H}}=$ $\left[\begin{array}{l}{\left[Z_{t}\right]^{T}} \\ {\left[Z_{t}\right]^{T}} \\ {\left[Z_{t}\right]^{T}}\end{array}\right]$, where $Z_{t}^{H}$ is a $3 \times 9$ matrix consisting of changes in exogenous variables, replicated for each row. ${ }^{13}$ This allows us to determine the yearly effects on price and quantities from observed changes in each exogenous variable, including the effects from the unexplained supply and demand shifts.

\section{Application}

We use E\&M's data to replicate the structural elasticities, presented in Table 1. We use R for all the estimation and calculations (R Development Core Team 2018). An R script containing all the code for the application is provided in the appendix. We refer to E\&M's original article for details on the choice of instrumental variables. The replicated elasticities provide us with the estimated effects of changes in exogenous variables on demand and supply. As in E\&M's original application, all coefficients are statistically significant, and DurbinWatson tests indicate no autocorrelation.

\footnotetext{
${ }^{12}$ When taking into account the time dimension in equations (13) and (14), we can interpret it as solving a system of three-dimensional arrays, where time is the third dimension that is added to the comparative statics model.

${ }^{13} \mathrm{Z}_{\mathbf{t}}^{\mathrm{H}}$ is a transformation of $\mathbf{Z}_{\mathbf{t}}$ where each column represents the change in an exogenous variable in year $t$. The transpose of $\mathbf{Z}_{\mathbf{t}}$ is replicated three times (hence three rows) to capture the impacts on each of the three endogenous variables when (element-by-element) multiplying $\mathrm{Z}_{\mathrm{t}}^{\mathrm{H}}$ with the reduced form elasticity matrix $\mathbf{E}_{\mathbf{t}}$.
} 
Inserting these into the economic model and solving equation (13) provides us with the full set of reduced-form elasticities, presented in Table 2.

The reduced-form elasticities in Table 2 provide the estimated general equilibrium effects. For instance, from Table 1 we see that an income growth of 1 percent causes an increase in demand per capita of 0.8 percent. Table 2 shows us that the general equilibrium effect of the income growth is a price increase of 1.3 percent, an increase in production of 0.3 percent, and an increase in consumption per capita of 0.3 percent. The increase in price caused by income growth has a negative effect on quantity demanded, which causes the net increase in consumption to be smaller than the increase in demand. To determine the driving forces behind the development of the US chicken market over time, and to evaluate the accuracy of our model, we investigate the results further in the following section.

\section{Results}

Our model now permits us to predict year-to-year price and quantity effects from changes in each specific exogenous variable. For brevity we focus on the effects of only one endogenous variable, namely price. ${ }^{14}$ We do this for two versions of the model: one where we set all unexplained supply and demand shifts to zero each year $\left(\ddot{P}_{t}\right)$ and one where we include the unexplained supply and demand shifts $\left(\dot{P}_{t}\right)$. In order to assess the impact over time from each

\footnotetext{
${ }^{14}$ Effects on production and consumption per capita can be found in the R code provided in the appendix.
} 
exogenous variable, we calculate cumulative impacts. The cumulative observed and predicted price and the predicted cumulative price effects from each exogenous variable are represented by indices in Table 3, with base year 1960 set to 100 . The index is calculated by adding the annual cumulative sums of price impacts (transformed to price impacts in levels) from each exogenous variable to the price in the base year, then dividing each value by the base year price and multiplying by 100 .

TABLE 3 ABOUT HERE

Comparing the actual price development $\left(P_{t}\right)$ with the predicted price $\left(\ddot{P}_{t}\right)$ when unexplained demand and supply shifts are set to zero, our model seems to explain the long-run price changes relatively well. The total predicted price decrease from 1960 to 1999 is 50 percent, compared to an actual price reduction of about 45 percent. As a general measure of goodnessof-fit, Table 4 shows the squared simple correlations between the observed and predicted endogenous variables (Hill et al. 2008), both in levels and in log differentials.

TABLE 4 ABOUT HERE

For $\ddot{P}_{t}$ in levels, the generalized $R^{2}$ is 0.80 , which appears reasonably high. However, in all but the last few years of our data, the predicted price level is higher than the actual price level. In 1979, for instance, the predicted price level is as much as 47 percent higher than the observed price level. Furthermore, the generalized $R^{2}$ for calculated relative change in price is only 0.26 . In other words, the predicted price level overstates the actual price level throughout most of the period, and a large part of the year-to-year price variation is not accounted for by changes in the exogenous variables. The generalized $R^{2}$ s for quantity produced and consumption per capita is very high when measured in levels, but close to zero for calculated relative changes in 
quantities. Unexplained changes in endogenous variables must be caused by unexplained shifts in supply or demand. By including the unexplained shifts in our model, predicted changes in prices $\left(\dot{P}_{t}\right)$ should by definition be nearly identical to actual price changes. ${ }^{15}$ When we include unexplained supply and demand shifts, the predicted cumulative decrease in chicken price $\left(\dot{P}_{t}\right)$ is about 43 percent, close to the actual reduction in price of about 45 percent. The predicted price level $\left(\dot{P}_{t}\right)$ now follows the actual price level $\left(P_{t}\right)$ closely throughout the entire period, with a deviation of no more than 4.8 percent in any year. ${ }^{16}$ The general $R^{2}$ for calculated price change is now 1 , and the general $R^{2}$ for the calculated price level is 0.999 .

Table 3 also shows the relative effect of each exogenous variable on US chicken price over time. Here, we must interpret our results with caution. Remember the usual assumption in econometric models; every structural elasticity is an estimate of the relative effect on demand (or supply) from a change in its corresponding exogenous variable, keeping all other variables constant. The assumption also holds for the general elasticities in our economic model. Looking at the results in Table 3, this assumption appears unrealistic. For instance, it seems unlikely that in the absence of changes in other exogenous variable, income growth would cause chicken prices to increase by 231 percent. Since our model does not account for interaction between exogenous variables we must interpret these results with this in mind. Nonetheless, the results in Table 3 still provide a good indication of the relative importance of each exogenous variable on the price development of US chicken. Income growth, export growth, and population growth have expanded demand and are the most important positive contributors on price. Supply shifts caused by technological change and long-run adjustments $\left(\alpha_{\mathrm{t}}\right.$ and $\left.\mathrm{QPROD}_{\mathrm{t}-1}^{\mathrm{a}}\right)$ are the most

\footnotetext{
${ }^{15}$ Remember our approximation and simplification in equation (6), which now should account for the remaining inaccuracy of our predicted endogenous variables.

${ }^{16}$ The maximum relative difference for a previous version of the model with variables expressed in relative changes is 2 percent. The reduction in accuracy in the current (log differences) version of the model is due to the approximation we do in the equilibrium condition (6): $\frac{z_{t}-z_{t-1}}{z_{t-1}} \approx \ln \left(\frac{z_{t}}{z_{t-1}}\right)$.
} 
important negative contributions on price. Prices of feed and beef have been less important. The net effect is a substantial reduction in price.

We have already established that unexplained shifts account for a substantial share of the year-to-year variation in prices. What are the cumulative effects of the unexplained shifts? Table 3 shows that unexplained demand shifts have had a cumulative positive effect on price of about 14 percent, while unexplained supply shifts have had a cumulative effect close to zero between 1960 and 1999. Looking at specific periods, some further observations can be made. To facilitate the interpretation of unexplained supply and demand effects as reported in Table 3, we illustrate their cumulative effects in Figure 1.

Unexplained demand shifts have had a negative effect on price between 1960 and the mid-1970s, with some year-to-year variation. This is followed by little change for about a decade. From the early 1980s until 1999 we observe unexplained demand growth almost every year, with the index moving upwards rather steadily from an all-time low of 80.8 in 1983 to an all-time high of 114.2 in 1999. Unexplained supply impacts appear to vary randomly, perhaps except between the years 1986 and 1996 where it seems to have been a relatively stable increase in unexplained supply causing price to go down. ${ }^{17}$

Although the main focus of this paper is on the approach per se rather than the specifics of the US chicken market, the apparent patterns of unexplained shifts justifies some consideration. While the unexplained shifts surely are due to numerous factors, the introduction of the broiler breeder Cobb 500 to the U.S market in the mid 1980’s might be part of the explanation behind

\footnotetext{
17 Thanks to an anonymous reviewer for noting this.
} 
the supply increase between 1985 and 1996. The Cobb 500 had a superior breast meat yield compared to existing breeders at the time, and has become so popular that today it is the world's most popular broiler breeder (Bugos 1992; Renema et al. 2007; The Poultry Site 2008).

What has caused the series of successive positive unexplained demand shifts since the early 1980s? Numerous hypothesis have been proposed to explain the increase in poultry consumption, such as health concerns causing consumers to substitute from beef to poultry (Moschini and Meilke 1989), increased number of women in the workforce directing meat consumption towards poultry products that more often than beef favor quick preparation or fast food (Haley 2001). Another argument is that changes in relative meat prices explain the increase in poultry consumption (Chalfant and Alston 1988). One possible explanation is the introduction of Chicken McNuggets at McDonalds in 1983 (Warren 2007), which coincides with the start of the long period of unexplained demand growth. Has the introduction of McNuggets caused a series of positive shifts in US chicken demand? Anecdotal evidence suggests McNuggets revolutionized chicken as a convenience and a frozen food (Buzby and Hodan 2006). Although McNuggets might be our prime suspect behind the unexplained demand growth since 1983, further investigation is necessary to establish a causal connection. Determining the size of the "McNugget effect" relative to other unidentified demand shifters warrants an econometric analysis that includes some variable(s) who could capture this effect. As noted by Haley (2001), the complexity of the dynamics of the U.S. meat industry makes it very difficult to attach a single explanation to the development of U.S. consumers' demand for meat.

Another issue is the causes of unexplained price variation. Are unexplained shifts in supply or demand more important causes of unexplained price variation? The range of unexplained supply impacts on price is between -20 and 15.2 percent, while the range of unexplained demand impacts is between -6.6 and 6.3 percent. Furthermore, standard deviations of 
unexplained supply and demand shifts are 4.8 percent and 2.4 percent, while standard deviations of price effects are 7.5 percent and 3.8 percent, both statistically different at a $1 \%$ significance level. The differences in range and standard deviations tells us that unexplained supply shifts contribute significantly more to unexplained price variation than unexplained demand shifts. Furthermore, the correlation between unexplained shifts in supply and demand is positive (0.34) and significant at the $5 \%$ significance level. ${ }^{18}$ While we cannot identify the reason for the positive correlation, there could be some unidentified variable(s) affecting both supply and demand simultaneously. As noted by a reviewer, these results might indicate omitted variable bias in E\&Ms econometric model. Although we acknowledge that the results might indicate the need for additional explanatory variables, availability of both data and degrees of freedom will always limit the number of explanatory variables in an econometric analysis. We also note that Brumm et al. (2008) find E\&Ms model to be satisfactory. Considering Brumm et al.’s (2008) results, Haley's (2001) comment on the complexity of the U.S meat industry, and our main objective of the paper, we err on the side of keeping the model as it is. We do take notice, however, that examining the unexplained demand and supply shifts may serve as a useful tool for indicating bias where traditional methods fail.

\section{Conclusion}

In this article, we bridge the gap between comparative statics and simultaneous econometric models. To do this we account for the impacts of unidentified supply and demand shifts in a comparative static model based on estimated coefficients from the econometric model. The procedure illustrates how applying a comparative statics economic model to the results from an econometric simultaneous equation model of supply and demand can provide substantial insight

\footnotetext{
${ }^{18}$ Frisch (1934) argues that there is no reason to expect supply and demand shifts to be uncorrelated.
} 
into the dynamics of price and quantity changes in a market. Using the same data in the comparative static model as was used in the simultaneous econometric model, we determine the relative effect of changes in specific exogenous variables on prices and quantities from period-to-period and over time. The accuracy of the specified supply and demand system is determined by the relative difference between predicted and observed price and quantity changes. To account for unexplained price and quantity variation, we calculate unexplained supply and demand shifts. Unexplained supply and demand shifts are defined as shifts (or shocks) in supply and demand that are due to causes other than changes in the exogenous variables included in the model. By calculating unexplained supply and demand shifts and introducing them as exogenous variables in our model, we determine the yearly effects on price from both known exogenous variables and unexplained supply and demand shifts. We apply the procedure on the US broiler chicken market between 1960 and 1999. Our economic model without unexplained shifts, based on a replicated econometric two-stage least squares model by Epple and McCallum (2006), explains long-term price changes rather well, but overstates the predicted price for long periods. Year-to-year predicted changes are inaccurate. When we take into account unexplained demand and supply shifts, yearly predicted price changes are nearly identical to the observed price changes. The introduction of Chicken McNuggets in 1983 coincides with a series of successive positive unexplained demand shifts, and might be a cause of structural shifts in chicken demand not accounted for in existing literature. Furthermore, we find that unexplained supply shifts account for a significantly larger share of unexplained price variation than unexplained demand shifts.

The procedure presented in this article can reveal valuable information about the development of a market. A comparative statics economic model with unexplained supply and demand shifts can be used to determine the relative effect of changes in specific exogenous variables on endogenous variables over time, to evaluate the implied accuracy of econometric 
models of supply and demand, and to evaluate the extent to which unexplained variation in price and quantities are driven by unexplained supply or demand shifts. The procedure is easily applied to the results from any econometric model of supply and demand. 


\section{Compliance with Ethical Standards:}

Eivind Hestvik Brækkan declares that he has no conflict of interest.

Øystein Myrland declares that he has no conflict of interest.

This article does not contain any studies with human participants or animals performed by any of the authors. 


\section{REFERENCES}

Abramovitz M (1993) The Search for the Sources of Growth: Areas of Ignorance, Old and New. J Econ Hist 53:217-243

Aigner D, Lovell CAK, Schmidt P (1977) Formulation and estimation of stochastic frontier production function models. J Econom 6:21-37

Alston JM, Norton GW, Pardey PG (1998) Science under Scarsity - Principles and Practice for Agricultural Research Evaluation and Priority Setting. CABI Publishing, Cambridge

Brumm HJ, Epple D, Mccallum BT (2008) Simultaneous Equation Econometrics: Some Weak-Instrument and Time-Series Issues. Working paper

Brækkan EH (2014) Disentangling supply and demand shifts: the impacts on world salmon price. Appl Econ 46:3942-3953

Brækkan EH, Thyholdt SB, Asche F, Myrland Ø (2018) The demands they are a-changin’. Eur Rev Agric Econ 45:531-552

Bugos GE (1992) Intellectual Property Protection in the American Chicken-Breeding Industry. Bus Hist Rev 66:127-168

Buse RC (1958) Total Elasticities. A Predictive Device. J Farm Econ 40:881-891

Buzby JC, Hodan AF (2006) Chicken Consumption Continues Longrun Rise. Amber Vawes 4:5

Chalfant JA, Alston JM (1988) Accounting for changes in tastes. J Polit Econ 96:391-410

Epple D, Mccallum BBT (2006) Simultaneous Equation Econometrics: the Missing Example. Econ Inq 44:374-384

Frisch R (1934) More pitfalls in demand and supply curve analysis. Q J Econ 48:749-755

Gilbert CL (2010) How to Understand High Food Prices. J Agric Econ 61:398-425

Gilbert CL, Morgan CW (2010) Food price volatility. Philos Trans R Soc Lond B Biol Sci 365:3023-34. doi: 10.1098/rstb.2010.0139

Haley MM (2001) Changing consumer demand for meat: the U.S. example, 1970-2000. In: Regmi A (ed) Changing Structure of Global Food Consumption and Trade. USDA, Agriculture and Trade Report WRS-01-1. Washington, DC, pp 41-48

Hill RC, Griffiths WE, Lim GC (2008) Principles of Econometrics, 3rd edn. John Wiley \& Sons, Hoboken, NJ

Marsh JM (2003) Impacts of Declining US Retail Beef Demand on Farm-Level Beef Prices and Production. Am J Agric Econ 85:902-913 
Meeusen W, van Den Broeck J (1977) Efficiency Estimation from Cobb-Douglas Production Functions with Composed Error. Int Econ Rev (Philadelphia) 18:435

Moschini G, Meilke KD (1989) Modeling the pattern of structural change in US meat demand. Am J Agric Econ 71:253-261

Muth RF (1964) The derived demand curve for a productive factor and the industry supply curve. Oxf Econ Pap 16:221-234

Piggott RR (1992) Some old truths revisited. Aust J Agric Econ 36:117-40

R Development Core Team (2018) R: A Language and Environment for Statistical Computing

Renema RA, Rustad ME, Robinson FE (2007) Implications of changes to commercial broiler and broiler breeder body weight targets over the past 30 years. Worlds Poult Sci J 63:457-472

Solow R (1957) Technical change and the aggregate production function. Rev Econ Stat 39:312-320

Taylor WE, Taylor LD (1993) Postdivestiture long-distance competition in the United States. Am Econ Rev 83:185-190

The Poultry Site (2008) How the Cobb 500 Changed the US Market. http://www.thepoultrysite.com/articles/1200/how-the-cobb-500-changed-the-us-market/. Accessed 19 Jan 2019

Tomek WG (2000) Commodity prices revisited. Agric Resour Econ Rev 29/2:125-137

Warren WJ (2007) Tied to the great packing machine: The Midwest and meatpacking. University of Iowa Press, Iowa City, IA

Wohlgenant MK (2011) Consumer Demand and Welfare in Equilibrium Displacement Models. In: Lusk, Roosen, Shogren (eds) The Oxford Handbook of the Economics of Food Consumption and Policy. Oxford University Press, Oxford

Zhao X, Mullen JDJ, Griffith GRG (1997) Functional forms, exogenous shifts, and economic surplus changes. Am J Agric Econ 79:1243-1251 


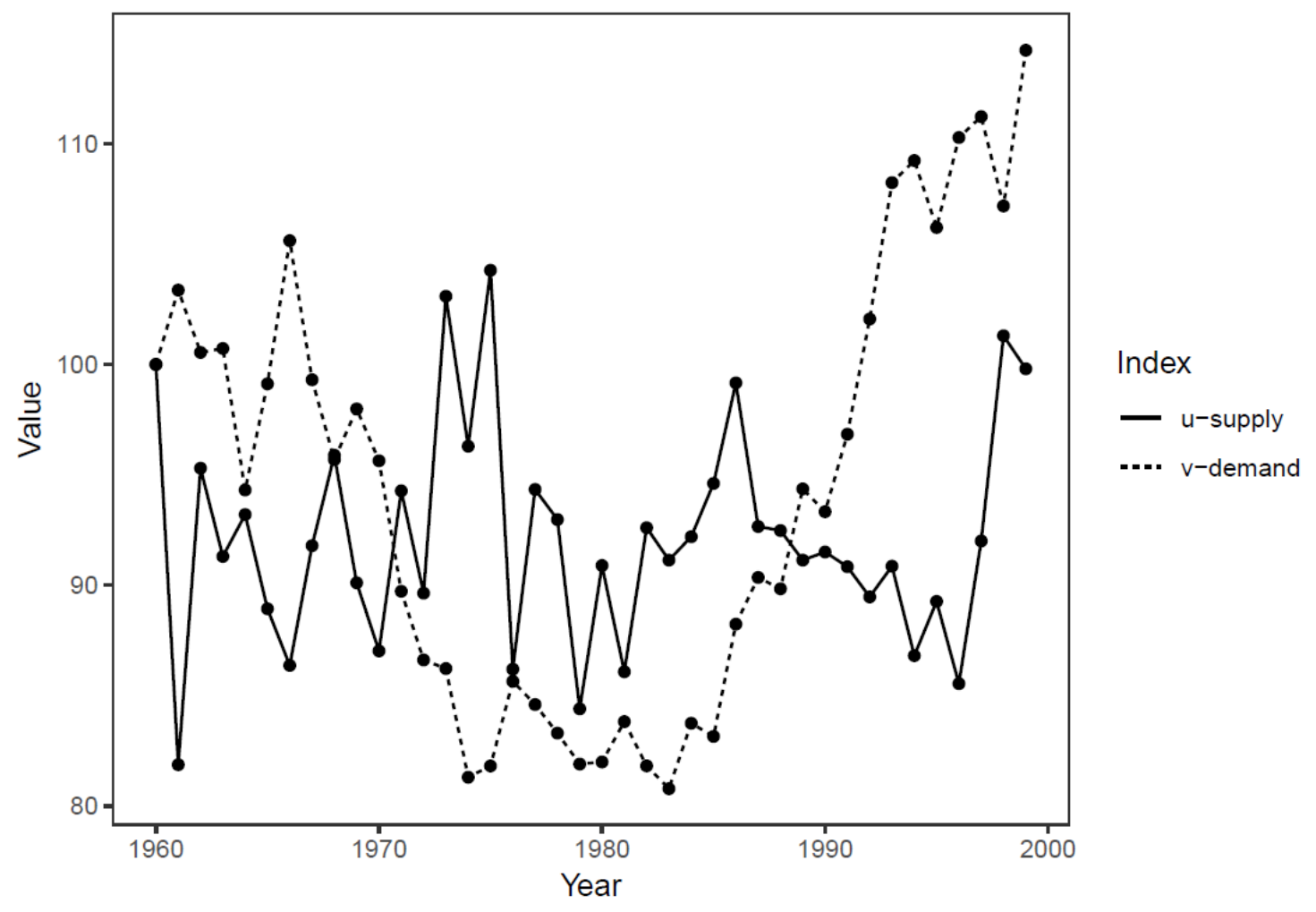


Table 1. Structural elasticities replicated from E\&M’s (2006) econometric model

\begin{tabular}{lr} 
Variable & \multicolumn{1}{l}{ Value } \\
\hline Price of chicken (supply) & $0.231^{* *}$ \\
Price of feed (supply) & $-0.148^{* * *}$ \\
\hline Time trend (supply) & $0.019^{* * *}$ \\
\hline Lag of production (supply) & $0.627^{* * *}$ \\
\hline Income (demand) & $0.841^{* * *}$ \\
\hline Price of chicken (demand) & $-0.397^{* * *}$ \\
\hline Price of beef (demand) & $0.275^{* * *}$
\end{tabular}

Notes: authors' own calculations, using data set provided in E\&M. ${ }^{* *}$ indicates statistical significance at the $5 \%$ level, ${ }^{* * *}$ indicates statistical significance at the $1 \%$ level 
Table 2. Reduced form elasticities from comparative static model

\begin{tabular}{lrrr} 
Exogenous variable & \multicolumn{2}{c}{ QPROD $^{\mathrm{a}}$} & $\mathrm{Q}$ \\
\hline Price of feed & 0.24 & -0.09 & -0.1 \\
Time trend & -0.03 & 0.01 & 0.01 \\
Lag of production & -1.03 & 0.39 & 0.41 \\
Population & 1.56 & 0.36 & -0.62 \\
Exports & 0.09 & 0.02 & -0.04 \\
Income & 1.31 & 0.3 & 0.32 \\
Price of beef & 0.43 & 0.1 & 0.1 \\
u - supply shifts & -1.65 & 0.62 & 0.66 \\
$\quad$ & 1.56 & 0.36 & 0.38
\end{tabular}

Note: reported values are means of estimated reduced-form elasticities throughout the period. 
Table 3. Cumulative price changes and price impacts of exogenous variables

\begin{tabular}{|c|c|c|c|c|c|c|c|c|c|c|c|c|}
\hline Year & $P$ & $\ddot{\boldsymbol{P}}$ & $\dot{\boldsymbol{P}}$ & $P F$ & time & $Q P R O D_{t-1}^{a}$ & $P O P$ & $X$ & $Y$ & $P B$ & $u$ & $v$ \\
\hline 1960 & 100 & 100 & 100 & 100 & 100 & 100 & 100 & 100 & 100 & 100 & 100 & 100 \\
\hline 1961 & 89.6 & 90.2 & 106.5 & 99.9 & 97.3 & 99.9 & 102.8 & 105.4 & 102.3 & 98.9 & 81.9 & 103.4 \\
\hline 1962 & 93.5 & 94.1 & 98.3 & 99.8 & 94.6 & 88.3 & 105.5 & 104.4 & 107 & 100 & 95.3 & 100.5 \\
\hline 1963 & 91 & 91.7 & 99.7 & 99 & 92 & 87.4 & 108 & 106.2 & 110.4 & 98.9 & 91.3 & 100.7 \\
\hline 1964 & 87.8 & 88.5 & 100.7 & 98.6 & 89.5 & 83.2 & 110.5 & 107.4 & 119.3 & 97 & 93.2 & 94.3 \\
\hline 1965 & 89.3 & 89.9 & 101.9 & 98.4 & 87 & 80.6 & 112.8 & 104.6 & 127.3 & 98.4 & 88.9 & 99.1 \\
\hline 1966 & 91.9 & 92.6 & 101.5 & 98.4 & 84.6 & 75.1 & 114.9 & 105.6 & 134.6 & 99.4 & 86.4 & 105.6 \\
\hline 1967 & 82.5 & 83.1 & 91.2 & 97.5 & 82.2 & 68.8 & 117 & 102.4 & 140.5 & 98.3 & 91.8 & 99.3 \\
\hline 1968 & 83.1 & 83.7 & 91.2 & 95.6 & 79.9 & 67.6 & 118.9 & 102.4 & 147.5 & 98.3 & 95.9 & 95.7 \\
\hline 1969 & 83.3 & 84 & 95.1 & 94.8 & 77.7 & 66.7 & 120.9 & 105.4 & 151.8 & 100.2 & 90.1 & 98 \\
\hline 1970 & 76.3 & 77.1 & 92.6 & 94.8 & 75.5 & 62 & 123.2 & 107.6 & 158 & 99.6 & 87 & 95.6 \\
\hline 1971 & 73.8 & 74.5 & 88.1 & 94.4 & 73.4 & 58 & 125.7 & 106.2 & 164.7 & 99.7 & 94.3 & 89.7 \\
\hline 1972 & 72.2 & 72.9 & 94 & 93.9 & 71.3 & 57.8 & 127.9 & 107.6 & 172.8 & 102.2 & 89.6 & 86.6 \\
\hline 1973 & 98.1 & 99.1 & 111.5 & 102.3 & 69.3 & 54.9 & 129.9 & 109.6 & 186.8 & 107.9 & 103.1 & 86.2 \\
\hline 1974 & 82.8 & 83.7 & 106.9 & 102.3 & 67.3 & 56.1 & 131.9 & 110.2 & 182.8 & 104.3 & 96.3 & 81.3 \\
\hline 1975 & 85.5 & 86.3 & 101.2 & 99.5 & 65.3 & 55.6 & 134 & 112.1 & 185 & 100.8 & 104.3 & 81.8 \\
\hline 1976 & 76.3 & 77.5 & 105 & 98.9 & 63.5 & 55.7 & 136 & 117.9 & 193.4 & 96.9 & 86.2 & 85.6 \\
\hline 1977 & 72.1 & 73.2 & 91.7 & 97.8 & 61.6 & 49.6 & 138.2 & 118.2 & 200.1 & 94 & 94.3 & 84.6 \\
\hline 1978 & 74.2 & 75.4 & 97.3 & 95.9 & 59.8 & 48.1 & 140.6 & 119.8 & 210.5 & 99.6 & 93 & 83.3 \\
\hline 1979 & 67.8 & 69.1 & 99.9 & 96 & 58 & 45.1 & 143 & 122.6 & 215.3 & 105.6 & 84.4 & 81.9 \\
\hline 1980 & 64.7 & 65.9 & 88.5 & 95.1 & 56.3 & 40.8 & 145.7 & 126.9 & 214.3 & 102.4 & 90.9 & 82 \\
\hline 1981 & 60 & 61.2 & 84.8 & 95 & 54.6 & 39.6 & 148 & 130.2 & 217.9 & 98.5 & 86.1 & 83.8 \\
\hline 1982 & 55.5 & 56.6 & 74.7 & 91.8 & 52.9 & 37.4 & 150.2 & 129.4 & 219 & 96.6 & 92.6 & 81.8 \\
\hline 1983 & 54.6 & 55.7 & 75.7 & 92.5 & 51.3 & 37 & 152.4 & 132.9 & 225.1 & 94.7 & 91.1 & 80.8 \\
\hline 1984 & 59.3 & 60.5 & 78.3 & 92.5 & 49.7 & 36 & 154.4 & 133.8 & 245.1 & 93.4 & 92.2 & 83.7 \\
\hline 1985 & 54.9 & 56 & 71.2 & 88 & 48.2 & 34.3 & 156.6 & 135.8 & 252.8 & 91.2 & 94.6 & 83.1 \\
\hline 1986 & 59.5 & 60.8 & 69.5 & 86.5 & 46.7 & 32.7 & 158.8 & 140.4 & 260.3 & 90.8 & 99.2 & 88.2 \\
\hline 1987 & 56.3 & 57.7 & 69 & 85.4 & 45.2 & 31.1 & 161 & 146.4 & 264.4 & 92.2 & 92.7 & 90.3 \\
\hline 1988 & 59.7 & 61.3 & 73.8 & 92.7 & 43.8 & 28.4 & 163.2 & 152.9 & 276.2 & 92.7 & 92.5 & 89.8 \\
\hline
\end{tabular}




$\begin{array}{rrrrrrrrrrrrr}1989 & \mathbf{6 2 . 5} & \mathbf{6 4 . 3} & \mathbf{7 4 . 8} & 90.8 & 42.4 & 27.3 & 165.6 & 163.7 & 281.8 & 93.3 & 91.1 & 94.4 \\ 1990 & \mathbf{5 8 . 3} & \mathbf{6 0 . 2} & \mathbf{7 0 . 5} & 87.5 & 41.1 & 25.1 & 168.2 & 172.4 & 285.8 & 94.2 & 91.5 & 93.3 \\ 1991 & \mathbf{5 4 . 6} & \mathbf{5 6 . 4} & \mathbf{6 4 . 2} & 85.8 & 39.7 & 23.3 & 171.6 & 178.1 & 282.6 & 93.7 & 90.8 & 96.8 \\ 1992 & \mathbf{5 3 . 1} & \mathbf{5 4 . 9} & \mathbf{6 0 . 1} & 84.8 & 38.4 & 21.8 & 174.9 & 181.7 & 288.7 & 92.5 & 89.5 & 102.1 \\ 1993 & \mathbf{5 3 . 9} & \mathbf{5 5 . 8} & \mathbf{5 6 . 8} & 85.2 & 37.1 & 20.2 & 178.3 & 185.6 & 289 & 92.8 & 90.9 & 108.2 \\ 1994 & \mathbf{5 3 . 4} & \mathbf{5 5 . 5} & \mathbf{5 8 . 5} & 85.5 & 35.9 & 19.1 & 181.5 & 204.8 & 293.8 & 91.5 & 86.8 & 109.2 \\ 1995 & \mathbf{5 2 . 7} & \mathbf{5 4 . 9} & \mathbf{5 7 . 9} & 85.2 & 34.7 & 17.5 & 184.7 & 224.4 & 298.9 & 90.2 & 89.3 & 106.2 \\ 1996 & \mathbf{5 4 . 9} & \mathbf{5 7 . 3} & \mathbf{6 0 . 8} & 90.2 & 33.5 & 16.6 & 187.7 & 239.4 & 303.6 & 89.1 & 85.5 & 110.3 \\ 1997 & \mathbf{5 5 . 8} & \mathbf{5 8 . 3} & \mathbf{5 6 . 9} & 87.1 & 32.3 & 15.6 & 190.9 & 246.8 & 310.3 & 88.9 & 92 & 111.2 \\ 1998 & \mathbf{5 5 . 3} & \mathbf{5 7 . 8} & \mathbf{5 3 . 2} & 81.8 & 31.1 & 14.9 & 194 & 250.8 & 325.4 & 88.3 & 101.3 & 107.2 \\ 1999 & \mathbf{5 4 . 9} & \mathbf{5 7 . 4} & \mathbf{5 0 . 4} & 76.2 & 30 & 14.6 & 197.2 & 262.6 & 330.8 & 88.2 & 99.8 & 114.2\end{array}$


Table 4. Generalized R-Square for predicted change and levels of endogenous variables

\begin{tabular}{ccccccc} 
& $\% d P$ & $\% d Q$ & $\% d Q P R O D^{a}$ & $P$ & $Q$ & $Q_{P R O D}$ \\
\hline$\dot{P}_{t}$ & 1 & 1 & 1 & 0.9999 & 1 & 1 \\
$\ddot{P}_{t}$ & 0.258 & 0.006 & 0.015 & 0.799 & 0.982 & 0.997
\end{tabular}

Notes: With $\left(\dot{P}_{t}\right)$ and without $\left(\ddot{P}_{t}\right)$ unexplained supply and demand shifts. Values reported in the table are squared simple correlations between predicted and actual levels and changes of the endogenous variables (Hill, Griffiths, and Lim 2008) 